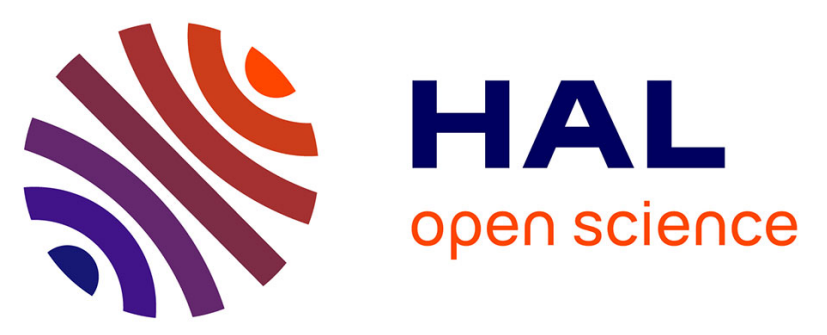

\title{
IN-SITU STUDIES OF ELECTROCHEMICAL INTERFACES USING X-RAY RADIATION AT GRAZING ANGLES. APPLICATION TO LIQUID MERCURY
}

Louis Bosio, Robert Cortès, M. Denoziere, Guy Folcher

\section{To cite this version:}

Louis Bosio, Robert Cortès, M. Denoziere, Guy Folcher. IN-SITU STUDIES OF ELECTROCHEMICAL INTERFACES USING X-RAY RADIATION AT GRAZING ANGLES. APPLICATION TO LIQUID MERCURY. Journal de Physique Colloques, 1989, 50 (C7), pp.C7-23-C7-27. 10.1051/jphyscol:1989703 . jpa-00229676

\section{HAL Id: jpa-00229676 https://hal.science/jpa-00229676}

Submitted on 1 Jan 1989

HAL is a multi-disciplinary open access archive for the deposit and dissemination of scientific research documents, whether they are published or not. The documents may come from teaching and research institutions in France or abroad, or from public or private research centers.
L'archive ouverte pluridisciplinaire $\mathbf{H A L}$, est destinée au dépôt et à la diffusion de documents scientifiques de niveau recherche, publiés ou non, émanant des établissements d'enseignement et de recherche français ou étrangers, des laboratoires publics ou privés. 


\title{
IN-SITU STUDIES OF ELECTROCHEMICAL INTERFACES USING X-RAY RADIATION AT
} GRAZING ANGLES. APPLICATION TO LIQUID MERCURY

\author{
I. BOSIO, R. CORTES, M. DENOZIERE and G. FOLCHER \\ Laboratoire LP 15 du CNRS "Physique des liquides et Electrochimie", \\ ESPCI, 10 rue vauquelin, F-75231 Paxis Cedex 05, France
}

\begin{abstract}
RESUME: Après un énoncé sommaire des méthodes permettant l'étude in-situ des interfaces électrochimiques au moyen des rayons $X$, on expose des résultats nouveaux relatifs la réflexion des rayons $X$ sur la surface du mercure liquide en contact avec sa vapeur ou un gaz inerte et, pour la première fois, en contact avec l'eau ou un electrolyte.
\end{abstract}

ABSTRACT: After a survey of the in-situ techniques used to probe the structure of electrochemical interfaces, we present new results obtained by specular X-ray reflectivity on the liquid-vapor, the liquid-gas and, for the first time, the liquid-water and liquid-electrolyte interface of mercury.

\section{INTRODUCTION.}

Despite the importance of the metal/electrolyte interface in fields such as energy storage, corrosion and electrochemical manufacturing, little is known about its structure. A theoretic description of the narrow transition region $<2 \mathrm{~nm}$ is a formidable problem due to i) the inherent inhomogeneity associated with any interface and $i i)$ the unknown double layer structure and the subsequent electronic perturbations to its surface. In turn, these are dependent on the many variables present: electrode composition, solvent, ionic charge and size and of course, the external potential. Experimental investigation is also hindered. The most powerful techniques are not sufficiently structure sensitive or require the transfer of the electrode to ultra high vacuum. Such a transfer from the solution raises questions about the true surface structure in-situ.

Althrough it is well now established that grazing incidence $X$-ray methods can be used to study structure at the solid/air or liquid/vapor interface, the significant penetration depth $X$-rays have in aqueous solution makes them well suited for in-situ electrochemical studies as well. All that is required is that the index of refraction for the solution is greater than that of the bulk electrode, and this is invariably the case.

There are three current ways of using $X$-rays at grazing incidence, namely, i) diffraction, ii) EXAFS and iii) specular reflectivity, but one can group them in $t$ wo general headings depending on whether or not the evanescent wave is used to probe structure, that is, if the incidence angle $\theta$ is lower or above the critical angle $\theta_{c}$ for total external reflection. Since our discussion is limited to grazing incidence methods, we have omitted, for instance, the structural determination of absorbates on single crystal electrodes by X-ray standing-waves.

\section{TOTAL REFLECTED X-RAY DIFFRACTION.}

Under conditions of total external reflection, the limiting penetration depth of the evanescent wave (typically some nanometers) offers the possibility of determining the structure of a surface layer. Two kinds of geometry can be used: in each case, the sample is illuminated at an angle $\theta$ smaller than $\theta_{c}$ and the detector is moved either in the in-plane configuration (probing correlations in the plane of the surface) or out of the plane (probing correlations perpendicular to the plane).

As an illustration of the use of the former geometry, we have chosen an in-situ grazing X-ray diffraction study of lead monolayers electrochemically deposited on silver and gold single crystals, recently reported [1]: the undexpotential deposition method used in this work allows for a precise control of the surface coverage from a fraction of a monolayer up to a full monolayer. It was found that the lead orders in an hexagonal closed packed geometry, with the lattice compressed 1.2 and $0.7 \%$ relative to the bulk lead, on silver and gold, respectively; the layer is incommensurate with the silver substrate and the lead crystal lattice is oriented relative to the silver 
with a $4.4^{\circ}$ rotational epitaxy angle. Such an experiment demonstrates the strength of the method for probing the in-situ structure of electrochemical interfaces.

Grazing-angle Bragg diffraction is not limited to crystalline materials: X-ray scattering from disordered systems contain information about the short-range structural order. For example, the transverse structure factor of the liquid-vapor interface of mercury has been determined using the method of grazing incidence diffraction [2]. The reason of such a study -and those described in the next sections related to the liquid mercury-consists in the controversy between theoretical or experimental results concerning the disposition of atoms at the surface. Two trends can be observed: either an exponentially decaying profile [3] or a spatially oscillating average ion-and electron-density profile [4-6]. In other words, the question can be formulated as follows: as one passes from the liquid metal to the vapor, does the density decrease monotonically over one or two atomic diameters (this is the normal behaviour for a liquid dielectric) or exhibit some oscillations indicating a stratified surface? The question has an additional part: what happens when the liquid metal is in contact with a solution?

The $\mathrm{X}$-ray scattering measurements from mercury-vapor interface, performed with the momentum transfer parallel to the liquid-vapor surface, show that, in a probed zone of about $3 \mathrm{~nm}$, the liquid structure is not very different from that in the bulk but the superficial region is possibly more dense; this conclusion rather supports the prediction of a stratified liquid-vapor interface density profile with high density strata at the surface.

\section{EXAFS STUDIES.}

Extended X-ray Absorption Fine Structure refers to the modulations in the X-ray absorption coefficient up to several hundred eV beyond an absorption edge. The advantage of EXAFS is that it can probe all forms of matter and gives information about the local environment around a particular element. Experimentally, the variation of the absorption cross section of the photoexcited atom may be determined using several detection modes; in the in-situ surface studies it is convenient to measure either the total reflected beam intensity or the fluorescence yield. The origin of the EXAFS modulations carried by the reflected beam comes from the fact that the refraction index $(n=1-\delta-i \beta)$ contains the absorption coefficient through $\beta$.

An application of the so-called RefleXAFS technique is given by the study of the films formed during the passivation of nickel and nickel-molybdenum alloys electsodes in $0.1 \mathrm{M} \mathrm{H}_{2} \mathrm{SO}_{4}$ solutions [7]. Passivation is a crucial factor in determining the capability of a metal to resist environmental attack and in any attempt to understand the passivation process, the in-situ composition and structure of the passive film must be known. In the above study, the film was found to be formed by Ni.O entities probably ordered perpendicularly to the surface, and a molybdenum enrichment in the superficial region was confirmed by an increase of the $\mathrm{Mg}$ edge amplitude.

A ReflEXAFS study from liquid-gas surface of mercury has been recently performed [8]. Actually, mercury is not a good canditate for EXAFS measurements. Nevertheless the pseudo-Debye-Waller factor depicting the atom disorder was found lower in the surface zone than in the bulk, and such assertion also supports an enhanced structurating in the surface fegion.

\section{MEASUREMENT OF REFLECTIVITY.}

The specularly reflected intensity from a surface depends on the variation of the index of ref raction along the normal to the surface so that the method offers the unique opportunity of probing the normal electron-density profile. To extract the density profile, one compares the curve experimentally measured to that calculated from a given model, using either the formalism for stratified medium [9] or the Fourier transform of the derivative of the density profile $[10\}$

It has however been demonstrated that the discrimination between several models can be made only if the reflectivity curve is known up to several times $\theta_{c}$. On solid electrodes, electrochemical action introduces a large degree of surface roughness which subsequently diminishes the specular reflectivity at angles above $\theta_{c}$. This difficulty may be overcome by performing the measurements on liquid metals: we report here the preliminary results of experiments designed to determine the density profile in liquid mercury in contact with an electrolyte, the applied potential corresponding to the point of zero charge. For comparison we have also determined the density profile in the liquid-vapor, liquid-nitrogen. gas and liquid water interface of mercury at room temperature.

In these experiments, particular attention was paid to the purity of mercury and the cleanness of the surface. Commercially available high purity $\mathrm{Hg}$ was further purified by chemical treatments [11], distilled under vacuum, and was poured in the glass sample holder through long glass capillaries. The surface was subsequently cleaned by suction. For the liquid-vapor studies, mercury was directly distilled into the glass sample container, and immediately studied under vacuum. 
The reflectometer previously described [12] was slightly modified: to increase the X-ray flux, only one LiF single crystal was used as monochromator in conjunction with a divergence slit $(50 \mu \mathrm{m}$ in width) and a guard slit $(70 \mu \mathrm{m})$; a slit $(50 \mu \mathrm{m})$ was put in front of the detector. For each incident grazing angle, the reflected beam was analyzed by moving the detector on both sides of the specular angle. We operated with a fine focus $X$-ray tube (2 kW Mo-anode).

To study the reflectance of liquid $\mathrm{Hg}$ in contact with a solution the pathlength through the solution should not exceed a value consistent with a tolerable absorption of the $\mathrm{X}$-ray beam (the characteristic absorption length for $\mathrm{H}_{2} \mathrm{O}$ is $9 \mathrm{~mm}$ for $\lambda=0.07 \mathrm{~nm}$ and $18 \mathrm{~mm}$ for $\lambda=0.05 \mathrm{~nm}$ ). But on account of the large convex meniscus induced by the high surface tension of liquid mercury, it can be demonstrated that, for a trough of such dimensions, the Hg surface does not possess sufficient flatness to allow X-ray reflectivity measurements. In our first attempt, we tried to use the surface curvature to disperse the reflected beam (fig. 1). By illuminating the sample with a horizontal and parallel beam and measuring the reflected intensity as a function of the reflected angle $2 \theta$, it is posssible to determine the reflectance of the surface. Unfortunately, even if a high flux beam of synchrotron radiation was used, we were unable to extract signal from the background for $\theta>3 \quad \theta_{c}$.

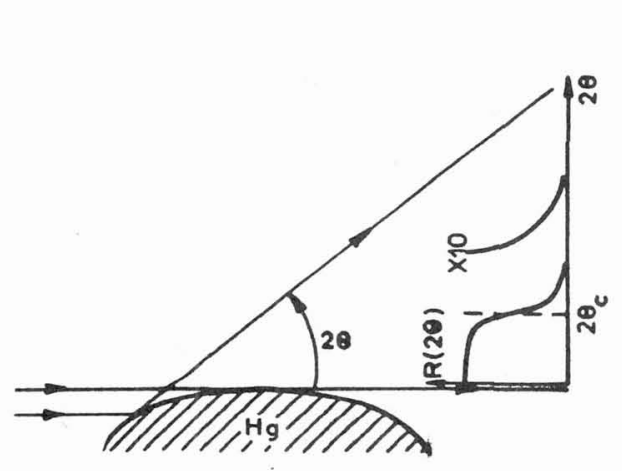

Figure 1: Geometry to disperse the reflected beam by the liquid mentscus.

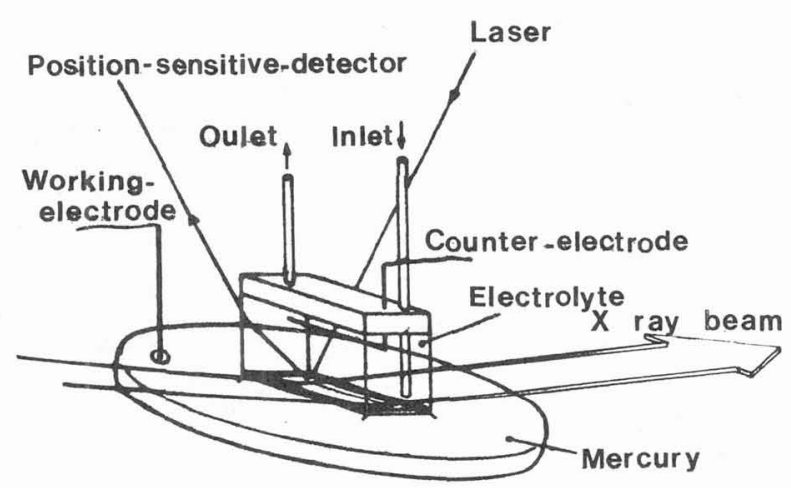

Figure 2: Device to obtain a flat solution/mercury interface.

We next performed experiments on large liquid $\mathrm{Hg}$ surface with the solution confined in a rectangular trough $(0.1 \mathrm{~mm}$ thick glass-wall) whose aperture, turned towards the $\mathrm{Hg}$ surface, was settled $0.5 \mathrm{~mm}$ above mercury, thus only the solution was in contact with the liquid metal (fig. 2). To correct for the concave depression formed on the Hg surface by the solution weight, a reduced pressure atmosphere was created over the solution. The regulation of the pressure inside the trough was ensured by means of an external pressure reservoir with feedback control by a laser/position sensitive detector which detected any deviation from flatness of the Hg surface. Another laser beam, in conjunction with a photodiode detector (not represented in fig. 2) was used to adjust and maintain the level of the interface constant in the $X$-ray beam. The sample holder and its accessories were, in turn, suspended by a $2 \mathrm{~m}$ cable from the ceiling to minimize vibrations. In electrochemical experiments, the applied potential was measured with respect to a reference electrode in contact with the trough by a liquid junction. We checked the efficiency of the method by noting that the beam reflected from the interface had the same width and shape as the incident beam put at the same scale (insert fig. $3, \theta=6 \quad \theta_{c}$ ).

\section{EXPERIMENT AL RESULTS.}

The results obtained both at the liquid/vapor and liquid/solution interfaces are reported in figure 3 . On curve a, the circles give the ratio $R / R_{F}$ of the reflectivity of the liquid-vapor interface as measured immediately after the sample preparation to the calculated Fresnel value. In fact, few hours after, the reflectance was progressively changed, and finally the reflectivity curve exhibited a shape similar to that shown in figure $3 b$. The crosses in figure $3 a$ are related to two sets of experiments performed at the liquid-dry nitrogen gas interface; here no evolution with time was detected over several days. (Note that the dispersion of the data points gives an idea of the experimental errors). From these results one can conclude that i) the reflectances of liqid mercury freshly distilled under vacuum or in contact with a dry inert gas are identical, ii) as previously stated [5], the 
hypothesis of a monotonously decaying density profile must be definitively ruled out: the dotted curve in figure 3a shows the best fitted exponential profile.

Starting from the density profile expression deduced by Monte-carlo simulations [4, eq.25], we have established a new expression in which, to account for the experimental data, the initial Lorentzian damping function has been replaced by a window so that:

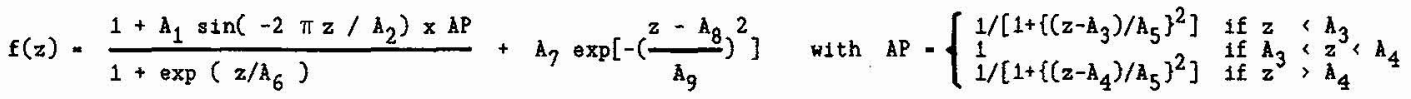

The best adjustment of the parameters $A_{i}$ to the experimental data is given in table $I$ and the resultant curve is shown by solid lines in figure 3 . Of course, we are aware of the non-uniqueness of the model, nevertheless, we observe very good agreement between the measured and the calculated curves up to $q=8 \mathrm{~nm}^{-1}$. The experimental data are well accounted for by assuming that the liquid-vapor and liquid-dry nitrogen gas interface is stratified parallel to the interface to a depth of 2-3 atomic diameters into the bulk liquid (see fig.3a').

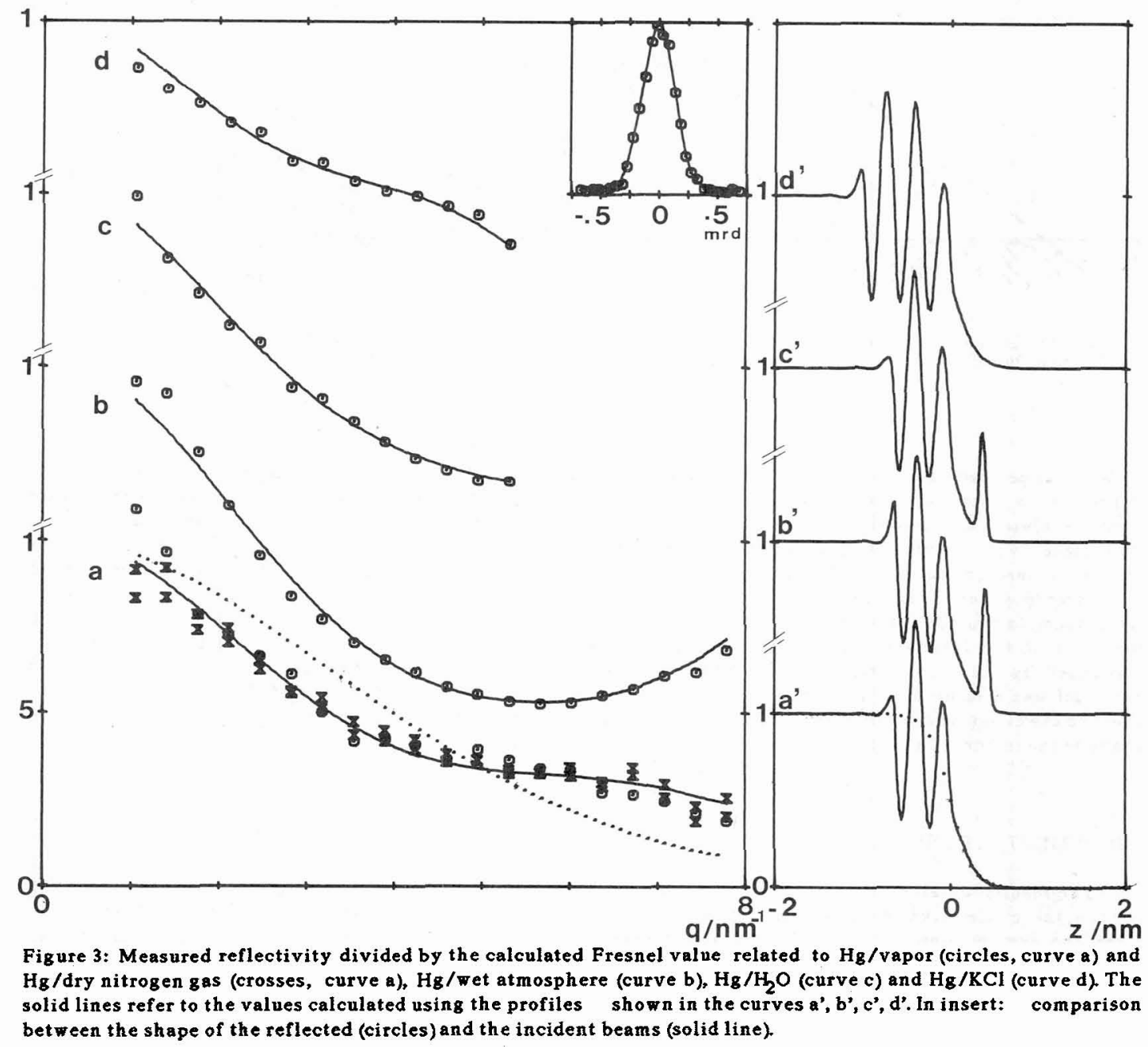


When the vacuum is deteriorated by the desorption of the container walls or if the liquid is exposed to ambiant air or to wet nitrogen gas, the reflectance of the surface has the shape given in figure $3 b$ (the circles are representative of averaged values from several measurements) on account of the formation of a layer represented by the gaussian in the expression giving $f(z)$ (see fig. 3b'). The chemical nature of this outer peak is unknown, although an oxide layer seems most plausible.

\begin{tabular}{|c|c|c|c|c|c|c|c|c|c|c|}
\hline 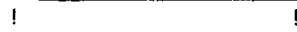 & ! & & & & $!$ & & $!$ & & & \\
\hline 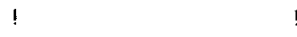 & $!$ & oscil & ating & part & $!$ & roughness & $!$ & ove & rlay & er \\
\hline 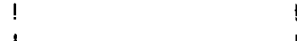 & $A_{1}$ & $A_{2}$ & $\mathbf{A}_{3}$ & $\mathbf{A}_{4}$ & $\AA_{5} !$ & $A_{6}$ & $!$ & $A_{7}$ & $\mathbf{A}_{8}$ & $A_{9}$ \\
\hline & $!$ & & & & & & & & & \\
\hline & ! & & & & $!$ & & ! & & & $!$ \\
\hline $\mathrm{Hg} /$ vapor: $\mathrm{Hg} / \mathrm{N}_{2}$ & .61 & .32 & -.62 & -.050 & $.036 !$ & .13 & ! & .0 & & \\
\hline ! Hg/atr; $\mathrm{Hg} /$ wet $^{2} \mathrm{~N}_{2}$ & .59 & .31 & -.62 & -.049 & $.036 !$ & .13 & ! & .71 & .39 & $.052 !$ \\
\hline$! \mathrm{Hg} / \mathrm{H}_{2} \mathrm{O}$ & .60 & .34 & -.63 & -.046 & $.036 !$ & .11 & ! & .61 & .36 & $.050 !$ \\
\hline $1 \mathrm{Hg} / \mathrm{KCl}$ & .62 & .33 & -.90 & -.053 & $.035 !$ & .13 & ! & .0 & & \\
\hline
\end{tabular}

TABLE I: Optimum fits for parameters $A_{1}$.

Curve $c$ (fig. 3) shows the ratio $R / R_{F}$ measured when mercury is in contact with water. The corresponding density profile (fig. $3 c^{\prime}$ ) and the fitted parameters (Table I) are identical to those found when liquid mercury is exposed to a wet atmosphere.

Finally, the results related to the liquid mercury in contact with an electrolyte are given in figure $3 \mathrm{~d}$; they concern an oxygen purged $0.1 \mathrm{M}$ potassium chloride solution ( $0.47 \mathrm{~V} / \mathrm{NCE}$ ), but almost similar results were obtained when 0.05 and $0.1 \mathrm{M} \mathrm{NaF}$ solutions were used. Compared to the free surface, the most striking points are the slightly increase of the oscillatory amplitude (fig. $3 \mathrm{~d}^{\prime}$, Table I) and also a more stratified interfacial zone. It is worthy of note that such behaviour has been predicted by Monte-Carlo simulations for a liquid metal in contact with a polar adsorbate [13\}. We have demonstrated that the difference in X-ray reflectivity versus angle of the incidence for the bare and covered surfaces is experimentally measurable.

\section{CONCLUSION.}

In the analysis of electrochemical data, we have shown that the $X$-ray studies at glancing angles can yield valuable information concerning the surface structure even on the arrangement of atoms in two dimentional systems or in regions with thicknesses of few several atomic layers. Several experiments have demonstrated the ability of various techniques which must be, of course, adapted to the specific problems encountered. We have given some results obtained by using three methods: grazing incidence diffraction, ReflEXAFS and $X$-ray reflectivity measurements. The new experimental results concern the structure of liquid mercury in contact with an electrolyte.

\section{ACKNOWLEDGEMENTS}

The authors would like to thank Dr. S.W. BARTON for a critical reading of the manuscript.

\section{REFERENCES}

[1] M.G.SAMANT, M.F.TONEY, G.L.BORGES, L.BLUM and O.R.MELROY. Surf. Sci. 193 (1988) L29 and M.G.SAMANT, M.F.TONEY, G.L.BORGES, L.BLUM and O.R.MELROY.J. Phys. Chem. 92 (1988) 220.

[2] S.W.BARTON, B.N.THOMAS, F.NOVAK, P.M.WEBER, J.HARRIS, P.DOLMERT, J.M.BOCH and S.A.RICE. nature 321 (1986) 685 .

[3] F.GREUTER, U.GUBLER, J.KRIEG, H.P.PREISWERRK and P.OELHAFEN. Surf. Sci. 124 (1983) 489.

[4] M.P.D'EVELYN and S.A.RICE. J. Chem. Phys. 78 (1983) 5081.

[5] L.BOSIO and M.OUMEZINE. J. Chem. Phys. 80 (1984) 959.

[6] A.TADJEDDINE, G.PIAZZA and M.COSTA. Europ. Lett. 5 (1988) 87.

[7] L.BOSIO, R.CORTES, P.DELICHERE, M.FROMENT and S.JOIRET. Surface and interface analysis $12(1988) 380$.

[8] L.BOSIO, R.CORTES, M.DENOZIERE and G.FOLCHER, to be published.

[9] F.ABELES. Ann. Phys. 5 (1950) 596.

[10]J.ALS-NIELSEN. Z. Phys. B: cond. matter 61 (1985) 411.

[11] M.E.NICHOLAS, P.A.JOYNER, B.M.TESSEM and M.D.OLSON. J. Phys. Chem. 65 (1961) 1373.

[12] L.BOSIO, R.CORTES,G. FOLCHER et M. OUMEZINE. Rev. Phys. Appl., 20 (1985) 437.

[13] Z.H.CAI, J.HARRIS and S.A.RICE. J. Chem. Phys. 69 (1988) 2427. 